\title{
Effects on apoptosis and cell cycle arrest contribute to the antitumor responses of interleukin-27 mediated by retrovirus in human pancreatic carcinoma cells
}

\author{
LIHUA LIU $^{1,2}$, JUN MENG $^{1}$, CONG ZHANG ${ }^{1}$, YUQING DUAN ${ }^{2}$, \\ LIANMEI ZHAO ${ }^{1}$, SHIJIE WANG ${ }^{2}$ and BAOEN SHAN ${ }^{1}$ \\ ${ }^{1}$ Research Center and ${ }^{2}$ Department of Clinical Cell Therapy, The Fourth Hospital of Hebei \\ Medical University and Hebei Cancer Institute, Shijiazhuang 050011, P.R. China
}

Received November 29, 2011; Accepted December 27, 2011

DOI: $10.3892 /$ or.2012.1663

\begin{abstract}
Interleukin (IL)-27, composed of p28 and EpsteinBarr virus-induced gene 3 (EBI3) subunits, has diverse functions in regulating immune systems. Human melanoma cells have been shown to express both IL-27 receptor subunits, and growth inhibition by IL-27 was detected. We investigated whether forced expression of the p28-linked EBI3 gene in human pancreatic carcinoma cells (AsPC1) by retroviral vector would produce IL-27-mediated antitumor effects and the related mechanisms. The data demonstrated that AsPC1 cells expressed both IL-27 receptor subunits, and tumor growth of AsPC1/IL-27 in mice was retarded compared with vector DNA-transduced tumors and survival of the mice was prolonged. Expression of cytokines such as interferon- $\gamma$, tumor necrosis factor- $\alpha$ and IL- $1 \beta$ in tumor specimens increased, while the secretion of IFN- $\gamma$ and TNF- $\alpha$ from spleen cells of mice bearing IL-27-transfected tumors increased. Moreover, cell cycle arrest was induced in AsPC1/IL-27 inoculated mice with upregulated p21 expression and downregulated survivin expression. The appearance of apoptotic cells increased in tumor specimens of mice bearing IL-27-transfected tumors compared with the mice bearing DNA-transfected tumors by confirming the expression of apoptosis-related proteins and activated apoptotic pathways through detection of cleaved PARP. These results suggest that transfection of the IL-27 gene into human pancreatic carcinoma cells could produce antitumor effects in vivo and induction of cell cycle arrest and apoptosis could be the mechanism of IL-27 action in tumor regression.
\end{abstract}

Correspondence to: Dr Baoen Shan, Research Center, The Fourth Hospital of Hebei Medical University and Hebei Cancer Institute, 12 Jiankanglu, Shijiazhuang 050011, P.R. China

E-mail: shan.hbyd@yahoo.com.cn

Key words: interleukin-27, antitumor, pancreatic carcinoma, apoptosis, cell cycle

\section{Introduction}

Tumor immunotherapy, including the use of cytokines and/ or modified tumor cell immune stimulatory cytokines, can enhance the innate and adaptive host antitumor immune response. Among the cytokines used for this strategy, interleukin (IL)-12 has attracted attention by its antitumor functions involved in activation of $\mathrm{T}$ and natural killer (NK) cells, antiangiogenic or apoptotic properties in both endothelial and tumor cells in the overall tumor rejection process $(1,2)$.

IL-27, one of the IL-12 family members, identified by disulfide-bonded heterodimeric cytokine composed of p28 and Epstein-Barr virus-induced gene 3 (EBI3) subunits that are structurally related to the p35 and the p40 subunits of IL-12 respectively (3), and it is primarily produced by dendritic cells (DCs) and macrophages. IL-27 receptor consists of two compontents: a unique WSX-1/TCCR and a common gp130 subunit (4). The biological functions of IL-12 and IL-27 are similar but not identical. IL-27 induces T-bet and IL-12R expression in naïve T cells, demonstrating that IL-27 plays a role in $\mathrm{T}$ cell maturation processes and generation of CTLs (5). The demonstration of significant antitumor activity in several preclinical animal tumor models has gained interest in the therapeutic use of IL-27 (6-10). The mechanisms underlying this antitumor activity are incompletely understood but may be related to the ability of IL-27 to stimulate T cells and NK cells (6-8), CD40 (9) or inhibit angiogenesis (10).

We have previously shown that the inflammatory cytokine IFN- $\gamma$ could be associated with the antitumour activity of IL-27 mediated by retroviral vector in a T cell-defective condition (6). Previous studies also showed that IL-27 has a direct antiproliferative activity on mouse and human melanomas through WSX-1/STAT1 signaling $(11,12)$. The antitumor activities of IFN- $\gamma$ are attributed to not only indirect mechanisms, such as immunomodulation, but also antiangiogenesis and direct actions on tumor cells (13). IFN- $\gamma$ is capable of potently inducing cell cycle arrest and apoptosis growth, resulting in growth suppression in a number of tumor models $(14,15)$. IFN- $\gamma$-induced apoptosis is mediated through regulating the expression of a number of apoptosis- 
related proteins, cell death receptors and their respective ligands, several Bcl-2 family members, and caspases $(15,16)$. Since tolerance to $\mathrm{T}$ cell mediated immunity is often induced in cancer patients, IL-27 actions on tumor cells directly or indirectly under $\mathrm{T}$ cell-defective conditions could be crucial from the standpoint of cancer immunology. In this regard, we established human pancreatic carcinoma cells expressing IL-27 and investigated IL-27-mediated antitumour responses in nude mice.

We report here, for the first time, the ability of IL-27 to influence cell cycle arrest and apoptosis together with the production of cytokines such as IFN- $\gamma$ and TNF- $\alpha$ in vivo. Cell cycle arrest and apoptosis has been implicated as a potential regulator of tumor development, outgrowth and metastasis $(17,18)$. We hypothesize that, in addition to its antiangiogenic activity and its ability to activate $\mathrm{T}$ and NK cells, the ability of IL-27 to induce cell cycle arrest and apoptosis may contribute to its antitumor activity.

\section{Materials and methods}

Cells and mice. Human pancreatic carcinoma cells (AsPC1) were originally obtained from the American Type Culture Collection (ATCC, Rockville, MD, USA) and cultured in RPMI-1640 supplemented with 10\% fetal calf serum (Sijiqing, Hangzhou, China), $100 \mathrm{U} / \mathrm{ml}$ penicillin and $100 \mathrm{mg} / \mathrm{ml}$ streptomycin in a humidified $5 \% \mathrm{CO}_{2}$ incubator at $37^{\circ} \mathrm{C}$ according to the standard cell culture procedures. BALB/c nu/nu mice (6-week-old females) were purchased from Chinese Academy of Medical Science (Beijing, China) and were maintained in specific pathogen-free conditions according to the guidelines of the animal experiment center of Hebei Medical University. All the animal experiments were approved by the animal experiment center of Hebei Medical University.

Transfection of tumor cells. AsPC1 cells were retrovirally transduced with the the p28 and EBI3 genes, which were linked with internal ribosomal entry site (IRES) (6). Briefly, AsPC1 cells were cultured with supernatants of PA317 cells producing LXSN retrovirus vector or the murine IL-27 (p28-IRES-EBI3) gene in the presence of $8 \mu \mathrm{g} / \mathrm{ml}$ polybrene (Aldrich, Milwaukee, WI, USA). G418 (800 $\mu \mathrm{g} / \mathrm{ml})$-resistant AsPC1 cells were established, with G418-resistant AsPC1 cells transduced with LXSN vector as the control.

$I L-27$ secretion. Cells were cultured at $2 \times 10^{5}$ cells/well in 24-well plates for $48 \mathrm{~h}$ and the cell-free culture supernatants were examined with an enzyme linked immunosorbent assay (ELISA) kit (R\&D Systems, Minneapolis, MN, USA) according to the manufacturer's instruction. The plates were read at $450 \mathrm{~nm}$ using an ELISA microplate reader set (Multiskan Ex, Lab Systems). Cytokine quantities in the samples were calculated from standard curves of recombinant cytokines using a linear regression method.

MTT assay. Cells $\left(1 \times 10^{3} / 50 \mu \mathrm{l}\right)$ were seeded into 96-well plates (BD Biosciences Labware). On days 1, 2, 3, 4, 5, 6 and 7, $10 \mu 1$ of MTT (Sigma-Aldrich, Germany) solution $(5 \mathrm{mg} / \mathrm{ml}$ in RPMI-1640 with 10\% FCS) was added to each well. Plates were incubated for $4 \mathrm{~h}$. Next, the MTT solution was removed and $100 \mu 1$ of DMSO (Sigma-Aldrich) was added to each well. The absorbance was read at a wavelength of $492 \mathrm{~nm}$ on an ELISA microplate reader set.

Animal experiments. Tumor cells engineered to overexpress IL-27 or empty vector alone were injected s.c. into the rightflank of mice with $1 \times 10^{7}$ tumor cells in $0.1 \mathrm{ml}$ of PBS and then monitored for tumor growth. Twelve mice were included for each group in random. Tumor volume was calculated according to the formula $\left(1 / 2 \times\right.$ length $\mathrm{x}$ width $\left.{ }^{2}\right)$.

Assays for IFN- $\gamma$ and $T N F-\alpha$. Spleen cells from naive mice or those injected with tumor cells $\left(5 \times 10^{6}\right)$ were cultured with 30 Gy-irradiated parental cells $\left(5 \times 10^{5}\right)$ in 24 -well plates for $48 \mathrm{~h}$. The concentrations of IFN- $\gamma$ and TNF- $\alpha$ in cell-free supernatants were examined with respective ELISA kits (BD Bioscience) according to the manufacturer's instructions.

Flow cytometry. Apoptosis was assessed by flow cytometric analysis of cells stained with Annexin-V-FITC and propidium iodide (PI) according to the manufacturer's instruction (BD Biosciences). Cell cycle analysis was performed using PI. Single-cell suspensions were obtained from tumor specimen of mice that were injected with different tumor cells and resuspended in ice-cold PBS, fixed in 70\% ice-cold ethanol. After treatment with RNase A, the cells were stained with PI and analyzed by using a FACscan flow cytometer (Beckman Coulter, CA). The data were analyzed with Expo 32 ADC software.

In situ detection of apoptosis. DNA strand breaks in apoptotic cells were measured by terminal deoxynucleotidyl transferasemediated dUTP nick end labeling (TUNEL) assay using the in situ Detection Kit (Roche Molecular Biochemicals, Mannheim, Germany). Slides were fixed with $4 \%$ paraformaldehyde solution and incubated in a $0.1 \%$ Triton X-100 permeabilization solution on ice. Slides were then rinsed twice in PBS and loaded with $50 \mu 1$ of the TUNEL reaction mixture and left for reaction at $37^{\circ} \mathrm{C}$ for $60 \mathrm{~min}$ in a dark, humidified chamber. Slides were again rinsed three times in PBS and incubated for $30 \mathrm{~min}$ with $50 \mu \mathrm{l}$ of the Converter-POD followed by another $10 \mathrm{~min}$ with diaminobenzidine to detect TUNEL labeled cells. Under light microscopy, the apoptotic index was calculated as the percentage of TUNEL-positive nuclei by scoring 500 cells using an ocular grid at x400 magnification.

Confirmation of gene expression by reverse transcriptionpolymerase chain reaction $(R T-P C R)$. For the reverse transcription-polymerase chain reaction (RT-PCR) analysis, total RNA was extracted with TRIzol (Invitrogen, Carlsbad, CA, USA) from tumor tissues on Day 9 after inoculation. First-strand cDNAs were prepared with SuperScript RT (Invitrogen) and were amplified with TaqDNA polymerase (Invitrogen) and PCR analysis was performed using selective primers (Table I) (synthesized at Sangon, Shanghai, China). Amplification was performed with 25-30 cycles under the following conditions: $5 \mathrm{sec}$ at $95^{\circ} \mathrm{C}$ for denaturation, $10 \mathrm{sec}$ at $60^{\circ} \mathrm{C}\left(\mathrm{GAPDH}\right.$ and WSX-1), $63^{\circ} \mathrm{C}(\mathrm{IFN}-\gamma), 59^{\circ} \mathrm{C}$ (p28 and $\mathrm{EBI} 3), 56^{\circ} \mathrm{C}$ (TNF- $\alpha$ and gp130) or $55^{\circ} \mathrm{C}$ (IL-1 $\beta$ ) for primer annealing and $1 \mathrm{~min}$ at $72^{\circ} \mathrm{C}$ for primer extension. The 
Table I. Primers used in the reverse transcriptase polymerase chain reaction.

\begin{tabular}{|c|c|}
\hline Name & Sequence \\
\hline$G A P D H$ & $\begin{array}{l}\text { F: 5'-ACCACAGTCCATGCCATCAC-3' } \\
\text { R: 5'-TCCACCACCCTGTTGCTGTA-3' }\end{array}$ \\
\hline$p 28$ & $\begin{array}{l}\text { F: 5'-GTTGCTGCCACCCTTGCTTCT-3' } \\
\text { R: 5'-GGCACTAAGGGCTCAGTCAG-3' }\end{array}$ \\
\hline$E B I 3$ & $\begin{array}{l}\text { F: 5'-GCCACAGAGCATGTCCAAGCTGCTCTTC-3' } \\
\text { R: 5'-CAGGATCCTCAGGGCTTATGGGGTCGAC-3' }\end{array}$ \\
\hline$W S X-1$ & $\begin{array}{l}\text { F: 5'-TGGACTTTTCCGAGGATGAC-3' } \\
\text { R: 5'-GGAGCAGCAGCAGGTAATTC-3' }\end{array}$ \\
\hline gp130 & $\begin{array}{l}\text { F: 5'-TGCTGATTGCAAAGCAAAC-3' } \\
\text { R: 5'-CCCACTTGCTTCTTCACTCC-3' }\end{array}$ \\
\hline$I F N-\gamma$ & $\begin{array}{l}\text { F: 5'-GCATCGTTTTGGGTTCTCTTGGCTGTTACTGC-3' } \\
\text { R: 5'-CTCCTTTTTCGCTTCCCTGTTTTAGCTGCTGC-3' }\end{array}$ \\
\hline$T N F-\alpha$ & $\begin{array}{l}\text { F: 5'-TCTCAGCCTCTTCTCATTCC-3' } \\
\text { R: 5'-TACTTGGGCAGATTGACCTC-3' }\end{array}$ \\
\hline$I L-1 \beta$ & $\begin{array}{l}\text { F: 5'-TCAGGCAGGCAGTATCACTC-3' } \\
\text { R: 5'-GCTCATATGGGTCCGACAGC-3' }\end{array}$ \\
\hline
\end{tabular}

amplified fragments were detected in $1.5 \%(\mathrm{w} / \mathrm{v})$ agarose gel and analyzed using an IS1000 image analysis system (Alpha Innotech, San Leandro, CA, USA).

Western blot analysis. Tumor tissues on Day 9 after inoculation were lysed with a protease inhibitor cocktail (Sigma-Aldrich, St. Louis, MO, USA). The tissue lysates were subjected to sodium dodecyl sulphate polyacrylamide gel electrophoresis (SDS-PAGE) and were probed with anti-p21 antibody (Ab) (Santa Cruz Biotechnology), anti-survivin Ab (BD Biosciences), anti-Bax Ab, anti-Bcl-2 Ab (Santa Cruz Biotechnology) or anti-PARP Ab (Cell Signaling, Beverly, MA, USA). The membranes were developed with the Odyssey infrared imaging system (USA, LI-COR) according to the manufacturer's instructions. The same filter was re-probed with anti-GAPDH Ab (Sigma-Aldrich) as a control.

Statistical analysis. All data were presented as mean $\pm \mathrm{SE}$ and analyzed with SPSS 13.0. Comparisons of group means were assessed with one-way ANOVA, followed by the LSD test for statistical significance. Survival of mice was measured by Kaplan-Meier analysis with log-rank test. $\mathrm{P}<0.05$ was considered statistically significant.

\section{Results}

Establishment of IL-27-expressing cells. AsPC1 cells were transfected with vector DNA (AsPC1/LXSN) or the p28-IRES-EBI3 gene using amphotropic retrovirus-producing PA317 cells. Among 20 G418-resistant p28-IRES-EBI3 genetransduced cell colonies, we selected a colony (AsPC1/IL-27) that produced the largest amounts of IL-27 $(167.64 \pm 8.37 \mathrm{pg} / \mathrm{ml}$ for $2 \times 10^{5}$ cells for $48 \mathrm{~h}$ ). IL-27 in the supernatants of control (AsPC1/LXSN) cells was undetectable. Proliferation rates
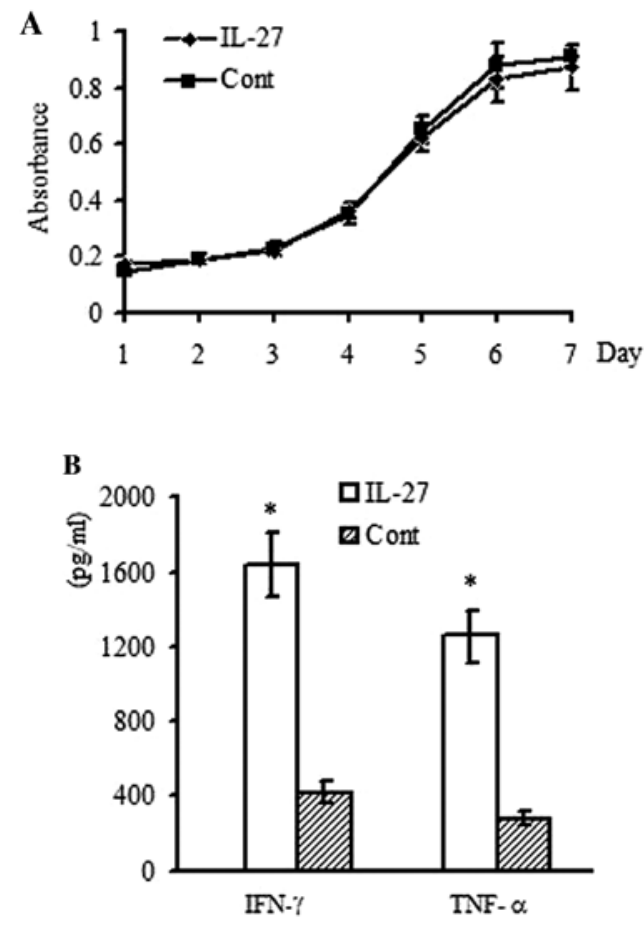

Figure 1. (A) Proliferation in vitro of vector DNA and IL-27 and transduced cells. Data represent the averages with standard error bars. (B) Production of IFN- $\gamma$ and TNF- $\alpha$ from PBMC that were cultured with supernatants of vector DNA and IL-27 transduced cells. Asterisks indicate P $<0.05$ (IL-27 vs. vector DNA control group). Data represent the averages with standard error bars.

in vitro of AsPC1/IL-27 cells remained the same as that of control group (Fig. 1A). We examined the production of IFN- $\gamma$ and TNF- $\alpha$ from PBMCs that were cultured with supernatants of vector DNA and IL-27 transduced cells (Fig. 1B). The 
A

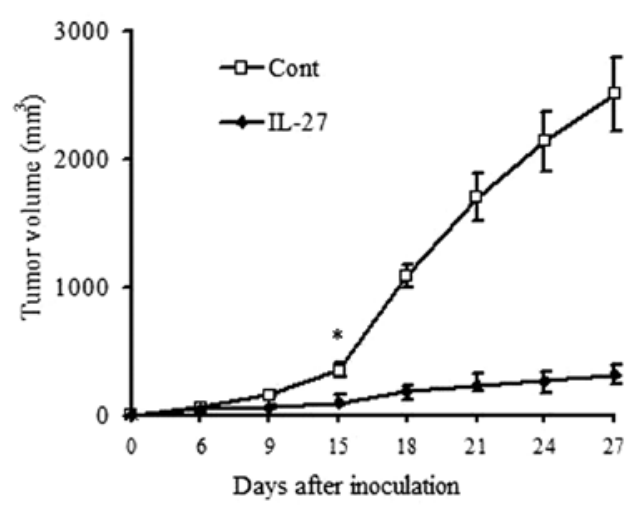

B

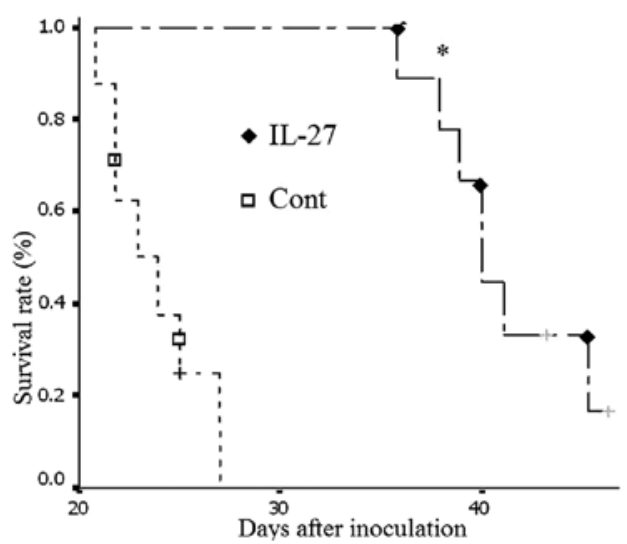

C

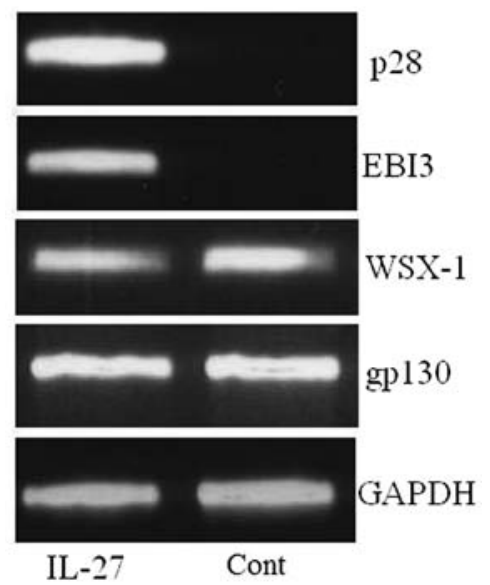

Figure 2. Antitumor effects of IL-27 in vivo. (A) Nude mice $(\mathrm{n}=24)$ were injected subcutaneously with different tumor cells (AsPC1/LXSN and AsPC1/IL-27) $1 \times 10^{7}$. Tumor volume was measured every 3 days. Asterisks indicate $\mathrm{P}<0.05$ (Day 15, IL-27 vs. vector DNA control group). Data represent the averages with standard error bars. (B) Survival of mice that were injected with vector DNA and IL-27 transduced tumor cells. Asterisks indicate $\mathrm{P}<0.001$ (Kaplan-Meier analysis with log-rank test). Data represent the averages with standard error bars. (C) Gene expressions of IL-27 (p28 and EBI3) and IL-27 receptors (WSX-1 and gp130) in tumor specimens of vector DNA and IL-27 transduced cells with RT-PCR. Tumor specimens were taken on Day 9. GAPDH expression was used as a control.

supernatants of AsPC1/IL-27 cells induced secretion of IFN- $\gamma$ and TNF- $\alpha$ greater than that of AsPC1/LXSN cells.
A

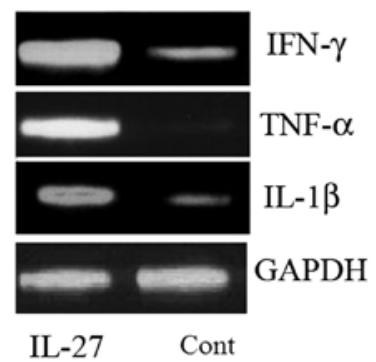

B

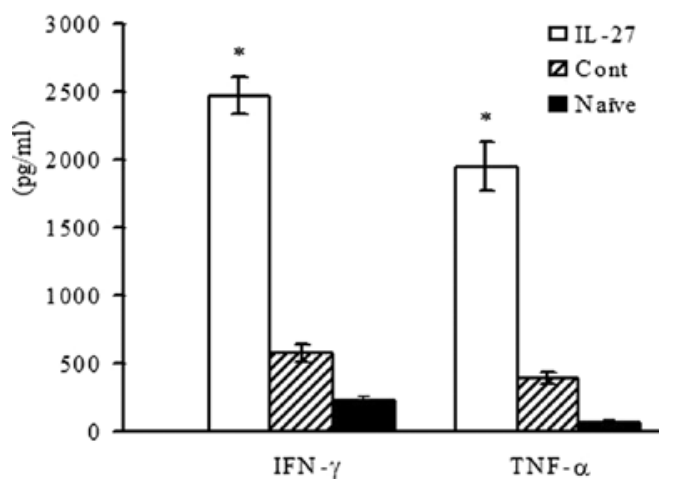

Figure 3. Cytokine production. (A) Gene expressions of IFN- $\gamma$, TNF- $\alpha$ and IL-1 $\beta$ in tumor specimens of vector DNA and IL-27 transduced cells with RT-PCR. Tumor specimens were taken on Day 9. GAPDH expression was used as a control. (B) Production of IFN- $\gamma$ and TNF- $\alpha$ from spleen cells of mice injected with vector DNA and IL-27 transduced cells were harvested on Day 9 after tumor inoculation. Asterisks indicate $\mathrm{P}<0.05$ (IL-27 vs. vector DNA control group). Data represent the averages with standard error bars.

Antitumor effects of IL-27 in vivo. To examine the antitumor activity of IL-27, differently transfected cells were subcutaneously inoculated into syngeneic nude mice, and tumor cell growth and survival rate of mice were compared in vivo. IL-27 transfected cells formed tumors but the growth was significantly retarded as compared with that of vector DNA-transfected cell injected mice (Fig. 2A). The survival of mice injected with IL-27 transfected cells (40.8 \pm 1.2 days) was significantly prolonged as compared with the control group (24.3 \pm 0.84 days) (Fig. 2B).

Tumor specimens were used to investigate whether IL-27 gene and its receptors expressed in vivo (Fig. 2C). RNA was extracted from tumors on Day 9 and the expressions of p28 and EBI3, WSX-1 and gp130 genes were examined with RT-PCR. Expressions of p28 and EBI3 genes were positive in the tumor specimen of mice injected with AsPC1/IL-27 cells and negative in mice injected with vector DNA-transfected cells, while for WSX-1 and gp130 genes, there was no significant difference in the two groups, suggesting that IL-27 was persistently expressed in tumor tissue of the IL-27 gene transfected group, which might combine with its receptors contributing to tumor rejection in vivo.

Effects on cytokine production. To examine the mechanisms underlying the antitumor activity of IL-27, we then analyzed cytokines expression (Fig. 3A). Expression levels of the IFN- $\gamma$, TNF- $\alpha$ and IL- $1 \beta$ genes in tumor specimens of 
A

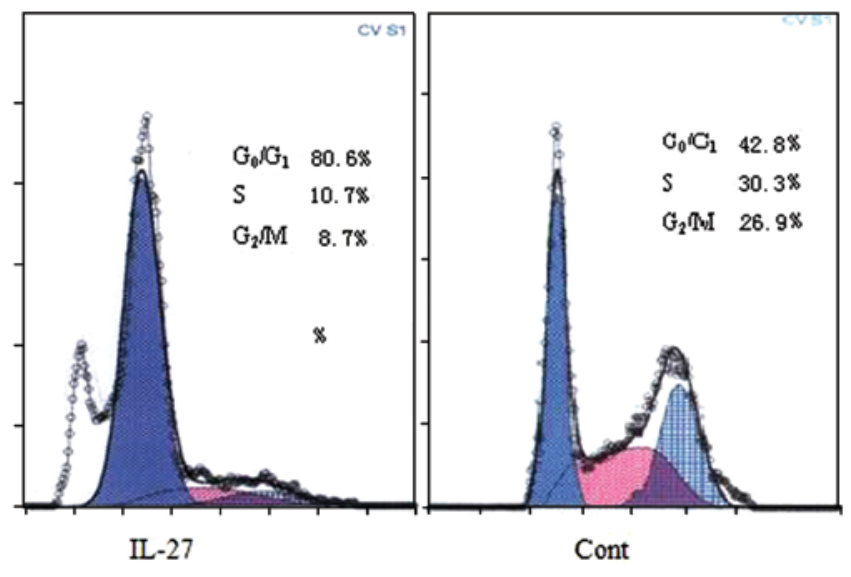

B

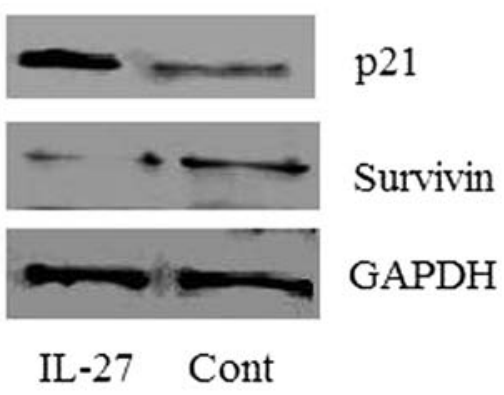

Figure 4. Cell cycle arrest induced by IL-27 in vivo. (A) Tumor specimen of mice that were injected with vector DNA and IL-27 transduced cells on Day 9 flow were assessed by flow cytometry, cell cycle analysis was performed using PI staining. (B) Protein expressions of p21 and survivin in tumor specimens of vector DNA and IL-27 transduced cells on Day 9 after tumor inoculation by western blot analyses.

AsPC1/IL-27 injected cells were greater than those of vector DNA-transfected tumors. Furthermore, production of IFN- $\gamma$ and TNF- $\alpha$ was analyzed to examine the cytokine production in spleen cells of tumor-bearing mice. The secretion of IFN- $\gamma$ and TNF- $\alpha$ in spleen cells of mice injected with AsPC1/IL-27 cells was greater than that in mice inoculated with vector DNA-transfected cells (Fig. 3B). These data suggest that in mice bearing IL-27 transfected tumors, IL-27 was able to enhance the cytokines production, which may contribute to its antitumor activity.

Effects of IL-27 on cell cycle arrest. Because IFN- $\gamma$ is known to possess direct antiproliferative activity and proapoptotic activity, we next examined whether IL-27 could exert similar effects using AsPC1 transfectants. Cells of tumor specimens were collected and their cell cycle distributions were analyzed by FACS (Fig. 4A). The results revealed that IL-27 increased the number of cells in G0/G1 phase in tumor specimens injected with AsPC1 expressing IL-27, but not in vector DNA-transfected tumors, showing that IL-27 significantly prevented cell cycle exit from G1 phase arrest. Furthermore, we examined the involvement of cell cycle inhibitor p21 and cell cycle regulator survivin. Expression of p21 was upregulated and survivin was downregulated in tumor specimens injected with

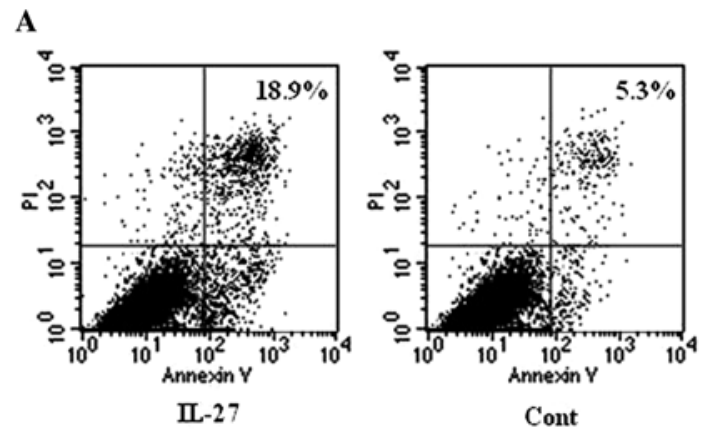

B

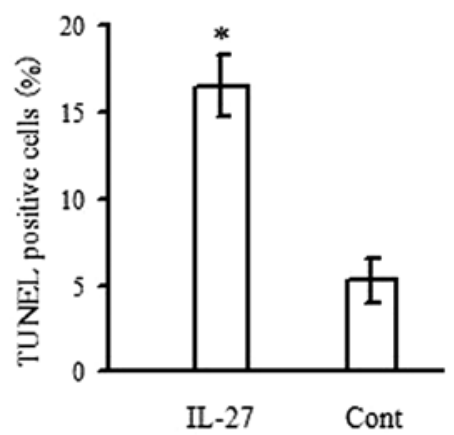

C

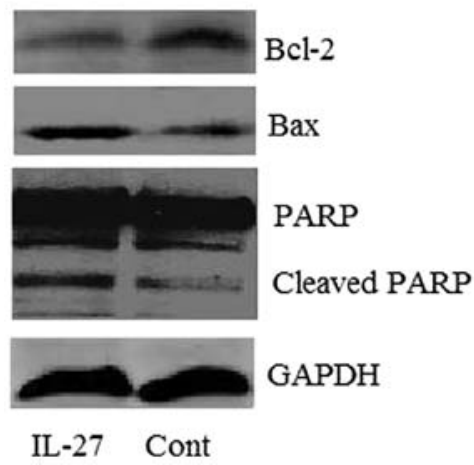

Figure 5. Apoptosis of tumor cells induced by IL-27 in vivo. (A) Flow cytometrical analyses with Annexin-V and PI staining in tumor cells of mice injected with vector DNA and IL-27 transduced cells on Day 9. (B) Tumor tissue section of vector DNA and IL-27 transduced cells on Day 9 after tumor inoculation was stained by TUNEL method for apoptotic cells. The number of TUNEL-positive cells and total cells were counted in 10 random microscopic fields. Asterisks indicate $\mathrm{P}<0.05$ (IL-27 vs. vector DNA control group). Data represent the averages with standard error bars. (C) Protein expressions of Bcl-2, Bax, PARP and cleaved PARP in tumor specimens of vector DNA and IL-27 transduced cells with western blot analyses. Tumor specimens were taken on Day 9. GAPDH expression was used as a control.

AsPC1/IL-27 cells, but not in vector DNA-transfected tumors (Fig. 4B). These results demonstrated that IL-27 induced cell cycle arrest in AsPC1/IL-27 inoculated mice with enhanced p21 expression and downregulated survivin expression.

Effects of IL-27 on apoptosis. To study the ability of IL-27 on apoptosis in vivo, we then examined flow cytometric profiles with Annexin-V and PI staining and demonstrated that IL-27 increased Annexin-V-positive and PI-positive population in tumor specimen of mice injected with IL-27 transfected cells, but not vector DNA-transfected tumors (Fig. 5A). Also, tumor 
section were subjected to TUNEL staining to observe cell apoptosis in situ (Fig. 5B). TUNEL-positive cells in the section of mice injected with IL-27 transfected cells was higher than that of mice inoculated with parental or vector DNA-transfected cells. Moreover, we examined the involvement of cell apoptosis regulator Bcl-2 and Bax (Fig. 5C). Expression of the Bcl-2 was downregulated and Bax was upregulated in tumor specimens injected with AsPC1/IL-27 cells, but not in vector DNA-transfected tumors. Western blot analyses also revealed the activated apoptotic pathways by detecting cleaved PARP in mice injected with IL-27 transfected cells (Fig. 5C). These data collectively indicate that after injection with AsPC1/ IL-27 cells, IL-27 was able to combine with its receptors and induced apoptosis in vivo.

\section{Discussion}

In this study, we demonstrated that IL-27 secreted from human pancreatic carcinoma cells could induce cell cycle arrest and apoptosis, suggested a possible use for cancer therapy. IL-27 has been demonstrated to be a cytokine with potential effects on T cells, DCs and macrophages (3-5). As a member of the IL-12 family, IL-27 is another IFN- $\gamma$-inducing cytokine with substantial preclinical antitumor activity in several preclinical models that include both gene therapy and recombinant IL-27 (6-9). The mechanisms underlying IL-27-mediated tumor regression may involve activation of $\mathrm{T}$ and $\mathrm{NK}$ cells or antiangiogenic properties in the tumor rejection process. Our previous study showed that secretion of IL-27 from human squamous esophageal carcinoma cells produced antitumor effects in T cell-defective mice by activation of natural killer cells and inflammation production (6).

Recent reports showed that IL-27 has a novel function to induce IL-10 or to inhibit Th17 activity involved in autoimmunity $(19,20)$. Previous studies showed that p28 suppressed the IL-17 production in transforming growth factor- $\beta$ - and IL-6-stimulating $\mathrm{CD} 4^{+} \mathrm{T}$ cells although not as efficiently as IL-27 and soluble p28 inhibited IL-27-dependent immune responses such as the enhancement of both IFN- $\gamma$ production and ICAM-1 expression $(21,22)$. The present study did not detect IL-17 gene expression in AsPC1-derived specimens. Our previous data showed that murine spleen cells cultured with IL-27 producedsecreted IFN- $\gamma$ together with IL-12. The present study with RT-PCR analyses on tumor specimens observed upregulation in particular in the IFN- $\gamma, T N F-\alpha$ and $I L-1 \beta$ genes, with ELISA assay on spleen cells showing the highest production of IFN- $\gamma$ and TNF- $\alpha$, also the cytotoxicity activity was increased (data not shown). IFN- $\gamma$ is known to possess direct antiproliferative activity and proapoptotic activity. TNF- $\alpha$ is involved in apoptosis of tumor cells in particular with chemotherapeutic agents and can be an adjuvant for T helper type 1 (Th1) responses (23). IL-1 $\beta$ triggers cell cycle arrest of tumor cells and can enhance IFN- $\gamma$ production from NK cells (24). In these conditions, we presume that cell cycle and apoptosis might be involved in alternative mechanisms in IL-27-induced IFN- $\gamma$ production in an in vivo setting.

Cell cycle analyses of the tumor cells demonstrated that IL-27 induced cell cycle arrest in the mice that were inoculated with the transfected human pancreatic carcinoma cells. IL-27 was previously shown has a direct antiproliferative activity on mouse and human melanomas through WSX-1/STAT1 signaling (11). The present data are the first to demonstrate that IL-27 could induce G0/G1 phase arrest with upregulation of p21 expression and downregulation of survivin expression and induced apoptosis through caspase-3-mediated apoptotic pathways, consequently revealing that IL-27 achieved antiproliferative activity through two mechanisms in human pancreatic carcinoma.

Apoptosis and cell cycle regulation are tightly orchestrated processes involving multiple effector molecules. The pathways that regulate cell cycle and cell survival overlap, but distinct mechanisms are involved. Earlier studies supported the view that p21 suppresses tumors by promoting cell cycle arrest in response to various stimuli (25). Additionally, substantial evidence from biochemical and genetic studies indicates that p21 acts as a master effector of multiple tumor suppressor pathways for promoting independent anti-proliferative activities (26). Survivin normally functions as an essential factor for chromosome segregation and cytokinesis during cell division (27). However, when overexpressed, survivin accumulates in the cytosol, where it assumes an anti-apoptotic function. This anti-apoptotic function of survivin may only be relevant to situations of overexpression of the classical p53 tumor suppressor pathway (28).

Since cell apoptosis is distinct from necrosis, in an effort to understand the apoptosis in the present mouse model, we detected either increased level of apoptotic tumor cells in IL-27 transfected tumors by combination of immunocytochemistry and TUNEL assay, or we performed the exclusion analysis of necrotic tumor cells by flow cytometry. The appearance of apoptotic cells in tumor specimens of mice bearing IL-27 transfected tumors were compared with the mice bearing DNA-transfected tumors. Apoptosis is an active cell death controlled by a discrete set of genes, and altering the expression of these genes or mimicking its transduction pathway could allow manipulation of its induction (29), therefore, we further evaluated the expression of apoptosis regulator $\mathrm{Bax}$ and $\mathrm{Bcl}-2$. The expression levels of the Bcl-2 was downregulated and Bax gene was upregulated in tumor specimens injected with AsPC1/IL-27 cells but not in vector DNA-transfected tumors. The control of apoptosis has been related to $\mathrm{Bax}$ and $\mathrm{Bcl}-2$ protein and activation of apoptosis may depend on the relative balance between Bax and Bcl-2. Bcl-2 is known as 'suppressor' and Bax appears to play a counterbalancing role by facilitating apoptosis (30). We confirmed the activated apoptotic pathways by detecting cleaved PARP in mice injected with IL-27 transfected cells.

In conclusion, inducing cell cycle arrest and apoptosis might be involved in mechanisms together with the production of cytokines such as IFN- $\gamma$ and TNF- $\alpha$ in IL-27-induced tumor regression in human pancreatic carcinoma cells in vivo. For the potentially lower toxicity, IL-27 may be a novel attractive candidate as an agent applicable to cancer immunotherapy with a potent antitumor activity in clinical and preclinical applications.

\section{Acknowledgements}

This research was supported by Grands-in-Aid from the National Natural Science Foundation of China. 


\section{References}

1. Del Vecchio M, Bajetta E, Canova S, Lotze MT, Wesa A, Parmiani G and Anichini A: Interleukin-12: biological properties and clinical application. Clin Cancer Res 13: 4677-4685, 2007.

2. Liu L, Wang S, Shan B, Sang M, Liu S and Wang G: Advances in viral-vector systemic cytokine gene therapy against cancer. Vaccine 28: 3883-3887, 2010.

3. Pflanz S, Timans JC, Cheung J, Rosales R, Kanzler H, Gilbert J, Hibbert L, Churakova T, Travis M, Vaisberg E, et al: IL-27, a heterodimeric cytokine composed of EB13 and p28 protein, induces proliferation of native $\mathrm{CD}^{+} \mathrm{T}$ cells. Immunity 6: 779-790, 2002.

4. Pflanz S, Hibbert L, Mattson R, Rosales R, Vaisberg E, Bazan JF, Phillips JH, McClanahan TK, de Waal Malefyt R and Kastelein RA: WSX-1 and glycoprotein 130 constitute a signaltransducing receptor for IL-27. J Immunol 172: 2225-2231, 2004.

5. Morishima N, Mizoguchi I, Okumura M, Chiba Y, Xu M Shimizu M, Matsui M, Mizuguchi J and Yoshimoto T: A pivotal role for interleukin-27 in $\mathrm{CD}^{+} \mathrm{T}$ cell functions and generation of cytotoxic T lymphocytes. J Biomed Biotechnol 2010: 605483, 2010.

6. Liu L, Wang S, Shan B, Shao L, Sato A, Kawamura K, Li Q, Ma G and Tagawa M: IL-27-mediated activation of natural killer cells and inflammation produced antitumor effects for human esophageal carcinoma cells. Scand J Immunol 68: 22-29, 2008.

7. Shinozaki Y, Wang S, Miyazaki Y, Miyazaki K, Yamada H, Yoshikai Y, Hara $\mathrm{H}$ and Yoshida H: Tumor-specific cytotoxic $\mathrm{T}$ cell generation and dendritic cell function are differentially regulated by interleukin 27 during development of anti-tumor immunity. Int J Cancer 124: 1372-1378, 2009.

8. Cocco C, Giuliani N, Di Carlo E, Ognio E, Storti P, Abeltino M, Sorrentino C, Ponzoni M, Ribatti D and Airoldi I: Interleukin-27 acts as multifunctional antitumor agent in multiple myeloma. Clin Cancer Res 16: 4188-4197, 2010.

9. Hu P, Hu HD, Chen M, Peng ML, Tang L, Tang KF, Matsui M, Belladonna ML, Yoshimoto T, Zhang DZ, et al: Expression of interleukins-23 and 27 leads to successful gene therapy of hepatocellular carcinoma. Mol Immunol 46: 1654-1662, 2009.

10. Shimizu M, Shimamura M, Owaki T, Asakawa M, Fujita K, Kudo M, Iwakura Y, Takeda Y, Luster AD, Mizuguchi J and Yoshimoto T: Antiangiogenic and antitumor activities of IL-27. J Immunol 176: 7317-7324, 2006.

11. Yoshimoto T, Morishima N, Mizoguchi I, Shimizu M, Nagai H, Oniki S, Oka M, Nishigori C and Mizuguchi J: Antiproliferative activity of IL-27 on melanoma. J Immunol 180: 6527-6535, 2008

12. Nagai H, Oniki S, Fujiwara S, Xu M, Mizoguchi I, Yoshimoto T and Nishigori C: Antitumor activities of interleukin-27 on melanoma. Endocr Metab Immune Disord Drug Targets 10: 41-46, 2010.

13. Pang KR, Wu JJ, Huang DB, Tyring SK and Baron S: Biological and clinical basis for molecular studies of interferons. Methods Mol Med 116: 1-23, 2005

14. Detjen KM, Farwig K, Welzel M, Wiedenmann B and Rosewicz S: Interferon- $\gamma$ inhibits growth of human pancreatic carcinoma cells via caspase-1 dependent induction of apoptosis. Gut 49: 251-262, 2001.

15. Merchant MS, Yang X, Melchionda F, Romero M, Klein R, Thiele CJ, Tsokos M, Kontny HU and Mackall CL: Interferon gamma enhances the effectiveness of tumor necrosis factorrelated apoptosis-inducing ligand receptor agonists in a xenograft model of Ewing's sarcoma. Cancer Res 64: 8349-8356, 2004.
16. Rosevear HM, Lightfoot AJ, O'Donnell MA and Griffith TS: The role of neutrophils and TNF-related apoptosis-inducing ligand (TRAIL) in bacillus Calmette-Guerin (BCG) immunotherapy for urothelial carcinoma of the bladder. Cancer Metastasis Rev 28: 345-353, 2009.

17. Nagata S: Apoptosis by death factor. Cell 88: 355-365, 1997.

18. Khan S, Aspe JR, Asumen MG, Almaguel F, Odumosu O, Acevedo Martinez S, De Leon M, Langridge WH and Wall NR: Extracellular, cell-permeable survivin inhibits apoptosis while promoting proliferative and metastatic potential. Br J Cancer 100: 1073-1086, 2009.

19. Murugaiyan G, Mittal A and Weiner HL: Identification of an IL-27/osteopontin axis in dendritic cells and its modulation by IFN-gamma limits IL-17-mediated autoimmune inflammation. Proc Natl Acad Sci USA 107: 11495-11500, 2010.

20. Sun J, Dodd H, Moser EK, Sharma R and Braciale TJ: CD4+ $\mathrm{T}$ cell help and innate-derived IL-27 induce Blimp-1-dependent IL-10 production by antiviral CTLs. Nat Immunol 12: 327-334, 2011.

21. Stumhofer JS, Laurence A, Wilson EH, Huang E, Tato CM, Johnson LM, Villarino AV, Huang Q, Yoshimura A, Sehy D, et al: Interleukin 27 negatively regulates the development of interleukin 17-producing $\mathrm{T}$ helper cells during chronic inflammation of the central nervous system. Nat Immunol 7: 937-945, 2006.

22. Shimozato O, Sato A, Kawamura K, Chiyo M, Ma G, Li Q and Tagawa M: The secreted form of p28 subunit of interleukin (IL)-27 inhibits biological functions of IL-27 and suppresses anti-allogeneic immune responses. Immunology 128: E816-E825, 2009.

23. Manusama ER, Nooijen PT, Stavast J, Durante NM, Marquet RL and Eggermont AM: Synergistic antitumour effect of recombinant human tumor necrosis factor alpha with melphalan in isolated limb perfusion in the rat. Br J Surg 83: 551-555, 1996.

24. Shen WH, Jackson ST, Broussard SR, Shen WH, Jackson ST, Broussard SR, McCusker RH, Strle K, Freund GG, Johnson RW, et al: IL-1 $\beta$ suppresses prolonged Akt activation and expression of E2F-1 and cyclin A in breast cancer cells. J Immunol 172: 7272-7281, 2004

25. Gartel AL and Tyner AL: The role of the cyclin-dependent kinase inhibitor p21 in apoptosis. Mol Cancer Ther 1: 639-649, 2002.

26. Abbas T and Dutta A: p21 in cancer: intricate networks and multiple activities. Nat Rev Cancer 9: 400-414, 2009.

27. Yang D, Welm A and Bishop JM: Cell division and cell survival in the absence of surviving. Proc Natl Acad Sci USA 101: 15100-15105, 2004.

28. Cho SJ, Lee SS, Kim YJ, Park BD, Choi JS, Liu L, Ham YM, Moon Kim B and Lee SK: Xylocydine, a novel Cdk inhibitor, is an effective inducer of apoptosis in hepatocellular carcinoma cells in vitro and in vivo. Cancer Lett 287: 196-206, 2010.

29. Banerjee S, Choi M, Aboukameel A, Wang Z, Mohammad M, Chen J, Yang D, Sarkar FH and Mohammad RM: Preclinical studies of apogossypolone, a novel pan inhibitor of bcl-2 and mcl-1, synergistically potentiates cytotoxic effect of gemcitabine in pancreatic cancer cells. Pancreas 39: 323-331, 2010.

30. Fletcher JI, Meusburger S, Hawkins CJ, Riglar DT, Lee EF, Fairlie WD, Huang DC and Adams JM: Apoptosis is triggered when prosurvival Bcl-2 proteins cannot restrain Bax. Proc Natl Acad Sci USA 105: 18081-18087, 2008. 